\title{
К ВОПРОСУ О СООТНОШЕНИИ ПРАВА И КУЛЬТУРЫ
}

\section{ON THE QUESTION OF RELATIONSHIP OF LAW AND CULTURE}

\section{Z. Kalandarishvili V. Zolotukhin}

Summary: This article examines the relationship between two social phenomena as law and culture, considering different scientific points of view. According to the authors, law should be attributed to the sphere of spiritual culture of people, because it literally permeates the entire spiritual culture of society.

Keywords: law, culture, society, religion, morality, mythology.

\author{
Каландаришвили Зураб Нодарович \\ К.ю.н., к.п.н., дочент, Санкт-Петербургский \\ Гуманитарный университет профсоюзов \\ zurab.kalandarishvili@yandex.ru \\ Золотухин Вячеслав Александрович \\ Аспирант, Санкт-Петербургский Гуманитарный \\ университет профсоюзов \\ t9119874369@gmail.com
}

Аннотация: В своей статье авторы исследуют соотношение двух таких социальных феноменов как право и культура, рассматривая различные научные точки зрения. По мнению авторов. право следует отнести к сфере духовной культуры людей, т.к. оно в буквальном смысле пронизывает всю духовную культуру социума.

Ключевые слова: право, культура, общество, религия, мораль, мифология.

деленной сфере, создающих модель мира и схему его изменения и позволяют индивидам сходно понимать социальные феномены и сходно действовать в определенных обстоятельствах [1].

Можно утверждать, что, являясь частью культуры, право вместе с тем отличается от других ее сфер, что и дает основания одновременно для сопоставления и противопоставления культуры и права. А именно:

- Право основано на исключительно рациональном, строго логичном подходе к жизни человека, к ее организации. Право сопровождает практически всю социальную и культурную историю человека. Право является необходимой предпосылкой и условием существования социального статуса личности как субъекта социума. Эмоциональность и, тем более, иррациональность в правовых отношениях однозначно оценивается как правовой «изъян», подрывающий основы права. В иных же сферах культуры эмоциональная составляющая является ценнейшим ее компонентом. Причем, иные внеправовые сферы культуры также выполняют функцию регулирования общественных отношений и организации бытия человека. Однако, в силу того, что духовная культура в своем арсенале имеет и внерациональные механизмы воздействия на человека, то она (в отличие от права) часто выступает источником регулирования общественных отношений на внерациональном уровне. Так, религия, по крайней мере в современных ее формах, апеллирует к вере, любви, душе; мораль - к совести, чести, долгу; искусство - к эмоциям, вдохновению, интуиции. И в этом смысле культура обращается к «праву неписанному». Безусловно, с развити- 
ем экономики, цивилизационных отношений, возрастанием материальных потребностей общества, все большее значение приобретают утилитарно-прагматические ценности, и, следовательно, нормы права становятся все более популярным регулятором общественных отношений (в том числе и в культурной сфере);

- Право принципиально отличается от других сфер культуры (религии, художественного творчества, философско-мировоззренческих установок и т. д.) прежде всего его отношением к категории свободы. Право, как нечто иное, есть некоторая система запретов, имеющих своей непосредственной задачей ограничение свободы воли человека. Хотим мы этого или нет, но право, в целях обеспечения порядка в обществе, вынуждено ограничивать действия людей в определенных рамках. Другие же сферы культуры, напротив, зачастую создают дополнительные механизмы самореализации для человека, преодолевают границы «социального бытия». Так, художественное творчество позволяет человеку создать иные миры, иные реальности, устанавливать в них свои «правила игры», законы и границы. Религия и философия компенсируют социальную несвободу человека, давая ему беспрецедентные возможности духовной самореализации и самовыражения. Конечно, и религия и мораль также решают вопросы об ограничении человеческого произвола, в отличие от права, они предлагают ему целый арсенал иных ценностей, основанных на понятиях любви, добра, красоты и истины. Наконец, право в меньшей степени, чем иные сферы духовной культуры является ее ядром и смыслообразующим элементом.

Если религия, мифология, мораль, художественное творчество, философско-мировоззренческие установки являются относительно устойчивыми системами, формирующими менталитет нации на протяжении столетий, то право - это система, не имеющая подобного рода постоянства. Мировоззрение, менталитет нации меняется на протяжении поколений; реформы права могут происходить из года в год. Конечно, в идеале право должно законодательно фиксировать устоявшуюся в обществе систему ценностей, основываться на философско-мировоззренческих ориентирах нации. Но на практике право лишь фиксирует достаточно изменчивую социально-политическую ситуацию в стране, точнее социально-политическую конъюнктуру социокультурных процессов. Все это позволяет нам сопоставлять понятия культуры и права. При этом право вместе с тем твердо держится внутри культуры своеобразными нитями, которые обеспечивают одновременную внутри культурную подвижность права. Подвижность в свою очередь дает праву возможность соприкасаться или тесно взаимодейство- вать с любыми иными подсистемами культуры, реагируя на малейшие их изменения.

Ввиду вышеизложенного, представляется достаточно очевидным, что понятие культуры по своему логическому содержанию шире понятия права. Более того, право - при известном подходе - лишь один из элементов структуры духовной культуры. В этом смысле культура есть своего рода «среда обитания» права, «система координат», в рамках которой оно формируется и действует. Своеобразным «мостом» между ними является правовая культура, выступающая одновременно как правовой аспект культуры и культурный аспект права. Право является культурной ценностью, но в разных обществах иерархическое место право в системе социальных ценностей разное. Культура, в том числе культура правовая обладает значительной силой исторической инерции наряду с подвижностью и гибкостью ее элементов. Отсюда её хорошая приспособляемость к изменяющимся историческим условиям, а также интеграция - в известной мере - в новую культуру, порожденную этими условиями.

С позиции социокультурного подхода следует определить право, как культурно исторический феномен, обусловленный многообразными проявлениями культуры (в том числе правовой), его устойчивостью и изменчивостью, пространственно-временной и этнокультурной целостностью. Право, являясь продуктом социальной культуры, возникает и развивается вместе с обществом $[2]$.

Ценность права как самостоятельного культурного явления находит конкретизацию в ценностях специального характера, относящихся к форме и содержанию права. Право не вырабатывает внутри себя собственной уникальной системы ценностей, а выступает формой обеспечения уже существующих ценностей общества.

Право в условиях диалога культур выходит за рамки национальных правовых систем и выступает в качестве элемента общецивилизационной культуры. Основное предназначение права - это обеспечение сохранения человеческой цивилизации через создание условий для взаимодействия и диалога между индивидами и социальными группами и институтами. Признание права природы и право человеческой культуры является необходимым условием для разработки комплексных мероприятий, направленных на правовое обеспечение природной среды, необходимой для существования человеческой цивилизации, а также на сохранение общемировой и национальной культуры - наследие [6].

Нам представляется, что право следует отнести к сфере духовной культуры людей, т.к. право в буквальном смысле пронизывает всю духовную культуру. Это можно 
сравнить с положением философии в культуре; философия является элементом культуры и способна осмыслить любой ее элемент. Будучи элементом культуры, право входит во взаимодействие со многими ее элементами, его главная задача - установление правовых отношений в соответствующей сфере культуры.

Таким образом, в вопросе соотношения права и культуры можно сделать следующие ключевые выводы:

Во-первых, культура представляет собой неоднородный организм, одной из структурных частей которого является право. При этом, право, являясь неотъемлемой частью духовной культуры, принципиально отличается от иных сфер культуры, что позволяет нам сопоставлять понятия культуры и права;

Во-вторых, право, как часть культуры существенно отличается от иных сфер культуры такими признаками, как стремление к предельной рациональности общественной жизни и отношений между людьми, установление пределов свободы человека, относительная нестабильность и гибкость по сравнению со смыслообразующими сферами культуры, зависимость права от изменения социально-политической ситуации в стране;
В-третьих, источники права в известной степени находятся за пределами основной деятельности права в пространстве коллективного сознания. Будучи частью чисто рационалистической модели мира право, во многом, опирается на источники, которые основаны на чувственном восприятии мира - такие как социальные мифы, обычаи, аксиологические установки. Это дает основания говорить о возможном противоречии и конфликте между ними (как источнике права) и самим правом, как системе, стремящейся к рациональной организации общественного бытия.

Какими бы ни были сложными процессы генезиса права в обществе, с точки зрения антропологической интерпретации, надо подчеркнуть тот факт, что право, представляет собой ценнейшее национально-культурное богатство и как социальный феномен с одной стороны является элементом и стороной культуры (относится к сфере духовной культуры), с другой стороны отличается от других сфер культуры, например искусства, мифологии, религии, философии, морали тем, что право, в определенном смысле, представляет собой некоторую систему запретов, имеющих своей задачей в охранительном назначении определенное ограничение свободы воли человека.

1. Гирц К. Интерпретация культур. М.: РОССПЭН, 2004. - 560 с.

ЛИТЕРАТУРА

2. Ромашов Р.А., Ветютнев Ю.Ю., Тонков Е.Н. Право - язык и масштаб свободы. - СПб.: Алетейя, 2015. - 448 с.

3. Ромашов. Р.А. Право: Нормативность и девиантность. - СПб.: Алетейя, 2018. - 330 с.

4. Сорокин П. Социальная и культурная динамика. - М.: Центр социологических исследований, 2000. - 1054 с.

5. Честнов И.Л. Социальное конструирование правовой идентичности в условиях глобализации // Диалог культур и партнерство цивилизаций. IX Международные Лихачевское научные чтения. - СПб., 2009. - С. 415.

6. Честнов И.Л., Исаев Н.А. Социокультурная антропология права. - СПб.: Алеф-Пресс, 2015. - 840 с.

7. Gehlen A. Studien Zur Anthropologie und Sociologie. Paris, 1963. - 355 pp.

○ Каландаришвили Зураб Нодарович (urab.kalandarishvili@yandex.ru ), Золотухин Вячеслав Александрович (t9119874369@gmail.com).

Журнал «Современная наука: актуальные проблемы теории и практики» 